\title{
Frame Walks Out
}

\author{
Mike Lloyd
}

\section{Walking-Out}

Most of us will have walked-out on someone, sometime. Most children 'run away from home', if only momentarily, and as adults we 'run away' not from our parents but our partners, again often momentarily. Some adopt the silent approach, relying more on gestures, others combine strategies, perhaps slamming a fist on a table whilst screaming 'I've had enough'. Whatever strategy is adopted, it is clear that walk-outs are a highly charged and significant social action.

Given a growing body of academic work on everyday life (e.g. Bell, 2001; Miller and McHoul, 1998), analysis of walk-outs could begin with a trawl through the literature; here, however, I want to take a different approach and focus on a single case. It is the story of a walk-out by Janet Frame, one of New Zealand's literary greats. Although my interest is sociological rather than literary, I hope to show that these two realms are deeply entwined.

In early adulthood, Janet Frame trained to be a school teacher. The significant walk-out in her life is a dramatic departure from the classroom on the day of a teaching inspector's visit. The conventional wisdom (e.g. Evans, 1977; Frame, 1984) is that this event marked her turning from the everyday world - a teaching career - to the world of the literary imagination. ${ }^{1}$ Michael King's recent 'authorised' biography (2000) presents a different version, or at least a change in emphasis from the versions of Frame and Patrick Evans. It is fitting, though, to begin with Frame's version as told in her autobiography.

It is 1945. Janet Frame has just turned twenty one, is training to be a primary teacher and is on section in a Dunedin school:

And now the year was passing quickly with the school
inspector's crucial final visit soon to be faced. Inevitably, one
bright morning of daffodils and flowering currant and a shine on
the leaves of the bush along Queen's Drive where I walked to
school each morning, of a hint of warm gold in the sharp lemon-
coloured sunlight, I arrived at school to find that it was the Day of
Inspection, and at midmorning the inspector and the headmaster
came to my classroom. I greeted them amiably in my practised
teacherly fashion, standing at the side of the room near the
display of paintings while the inspector talked to the class before

${ }^{1}$ It is also worth noting that this walk-out could be considered the first of many in her life. I owe this point to an anonymous referee; thanks also to this referee for other helpful comments. 
he settled down to watch my performance as a teacher. I waited. Then I said to the inspector, 'Will you excuse me a moment please?'

'Certainly, Miss Frame.'

I walked out of the room and out of the school, knowing I would never return. (Frame, 1984: 63)

Frame combines the story elements in a dramatic fashion, leaving us in no doubt that the 'Day of Inspection' is a Judgement Day. The theme of change is skilfully constructed using description of everyday surroundings: it is a bright morning with spring flowers out, a 'hint of warm gold in the sharp lemon-coloured sunlight'. The reader is left with little doubt that the walk-out was a natural occurrence - just as the seasons naturally change, so too did Frame's life. Moreover, it is a process of change over which she is partly in control, where she knows that a life devoted to the literary imagination was to replace the mundane world of teaching.

In contrast, King's version introduces more actors, carefully footnotes its sources, and seems to aim for a 'complete' account. The life story King tells is still captivating, but King seems preoccupied with veridicality, with the issue of faithfulness-to-reality. In King's version, the walk-out recedes into the background, with Frame's psychology lecturer, John Money, presented as the key actor:

The student Money was about to counsel in September 1945 would provide precisely the kinds of problems he would find interesting - and, for a 24-year old psychologist with no clinical training or experience, challengingly and hazardously complicated.

Frame came to Money's office in the attic of one of the university's old ivy-covered professorial houses on 19 September. She told him that she had walked out of her classroom at Arthur Street the previous week 'as the inspector walked in'. This was in part a consequence of her deep fear of being judged; but it was related, she said, to the fact that she was even more unconfident than usual because Money had passed her in the street the previous day without recognising her... Frame also told Money of her 'deep devotion to literature' and indicated it was in that direction that she would prefer to make a career. She had no wish to return to teaching, but had told her headmaster by telephone that she would produce a medical certificate to explain her sudden departure from school and continuing absence. (2000: 65-66)

In a footnote (33, ch. 4) King notes that his description of this period is substantially based on Money's records, which leads him to the view that 
Frame's autobiography in fact confuses the sequence of broader events occurring at this time. King's version presents the dominant concern in this period of Frame's life to be John Money, psychologist. This is consistent with King's framing of the walk-out as just one further step leading to 'an unravelling' (as the chapter is titled). This unravelling is, of course, Frame's first diagnosis of mental illness and first period of institutionalisation in a mental hospital.

Interestingly, the version in Patrick Evans' earlier biographical work is much like Frame's:

... she found herself early in 1945 in a classroom at the Arthur Street school in Dunedin ... Neither her teaching nor her university work survived the year: the confusing, contrary demands of classroom and staffroom alike epitomized "this" world, and long before the year ended she had walked away from the classroom and school, "from 'this' world to 'that' world where I have stayed, and where I live now," she later stated. Appropriately, it was an agent of the system who precipitated her departure: her classroom had two doors, and as an Inspector entered through one she vanished through the other, never to return. (1977: 29-30)

Evans makes no mention of an infatuation with a psychology lecturer; instead, he provides a powerful metaphor of vanishing through a door into a different world. Clearly, this portrayal preserves Frame's agency in the event: she walks away from the classroom; she vanishes through the door. This is consistent with Frame's earlier telling of the walk-out in the short essay 'Beginnings'. In this, she states, 'At first, it seemed a lonely disastrous choice. I tried to kill myself, and was sent to hospital for six weeks ...' (1965: 45), thus emphasising 'choice', even one which at times felt 'disastrous'.

Thus, there is a stark difference between the three versions. Frame and Evans favour agency: Frame knew teaching was a stopgap measure, her real desire was for the 'other' world of poetry and literature, and they both describe the walk-out in a dramatic, rhetorical, and literary style. In contrast, the implication of King's portrayal is to favour instability and institutional agency: Frame was unstable on a variety of fronts; the walk-out was just another instance of her inability to face the regularity demanded by institutions, particularly their judgements about the competency of an individual, and this became one further piece of evidence of personal unravelling on the road to a relatively lengthy engagement with mental health institutions. In short, we have two versions of the walk-out: one as an abrupt change, that is an 
epiphany, and a contrasting view where the walk-out is a continuation of an existing pattern that leads to an unravelling.

\section{Dissolving the Complications of Versions}

Brief as the above details are, it is clear that the story has many complications. We have Janet Frame, an author who creates both fictional narrative and autobiography. In our culture, we assume that a person has the 'facts' of their life available to them for recall and report to others - in a sense we 'possess' our life. However, this never approaches closure as the ability to recall can be doubted (e.g when there are questions about sanity), and, if no one is there to listen, our reports remain a private story. We all know that an engagement with mental health institutions featured in Frame's life, and just as clearly we know that Frame held to a view where autobiography was as much fiction as her 'truly' fictional work. It is also interesting to note that while Evans' version of the walkout is consistent with Frame's, his delving into her life incurred the wrath of Frame (see Evans, 1986). Then we have King, who in contrast to Evans, has direct access to Frame to write the biography. Being able to talk to the subject of a biography is related to the notion of 'possessing a life' - it is seen as the next best thing to the autobiographical account.

While these points, and the differences in the versions, seem like complications, there are two important clarifications. First, the versions of the walk-out are caught up in different 'recognisable practices' (Rawls, 2001). That is, they most emphatically are not accomplishing the same thing: Frame and Evans make the walk-out to be an epiphany, they tell it in a way that makes recognisable the social practice of epiphany, whereas King makes the walk-out to be a symptom of a much broader process - the inability of Frame to face judgement, thus leading to unravelling. So, the versions are engaged in working up different things, in making different 'recognisable practices'. Secondly, linked to this, it is important to stress that I am in no way suggesting that King is juxtaposing, comparing or contrasting his version to that of Frame or Evans. I am sure he is aware of differences, but he is not explicitly offering an alternative based on comparison.

These two clarifications may go some way to dissolving the apparent either/or choice between the versions; however, if choosing a more or less accurate version is not at stake here, what is the point? The answer is that looking closely at the particulars of the Frame story tells us important things about the walk-out as a social form, and about notions of the literary life. If for the meantime we put aside King's version of the walkout, some simple analytic points can be made. A notable feature of the epiphany version is its economy. It is told with remarkably little material - in fact, Evans' version is 
neatly encapsulated in the statement, 'her classroom had two doors, and as an Inspector entered through one she vanished through the other, never to return'. Understanding is there at-a-glance; the story calls forth an immediate response in the reader, not a puzzled search for meaning. Such economy raises the sociologist's interest, and while we need to be careful about overgeneralising, we can suggest that where practices are carried out with economy, they are all the more powerful.

Linked to this, we can suggest that the connection between economy and power has much to do with the reproduction of existing story-forms. The point is that the epiphany version is close to a moral tale, or parable, in form. Stories like it are widely dispersed in human culture: at heart the tale is a comparison and contrast between stability and change (e.g the Apollonian/Dionysian theme), where those who 'Seize the Day' or opt for the risk of change become the victors, or more morally empowered. Further, with the Frame walk-out story there is a more specific message (or actually, effect). Like all stories, moral tales must construct communities of readers they operate to construct a collectivity that shares something - and overlapping the more general message in the walk-out story there is a more specific message to the imaginative community, that is, the world of writers.

On this point, O'Sullivan's review of King is very useful:

This is a book about a woman who feared being judged, who suffered deeply because of wrong judgments, whose professional life and enormous gifts were then marshalled for decades to challenge and evade a world, variously crippled by those who judge. The Place of Judges is where most of us live. Those few who resist and erect a counterworld know language is their ultimate and often their only weapon, a living, vibrant force for defiance - the writer as perpetual revolutionary against the zombie-speech of convention. (2000: 1, emphasis added)

Frame is a New Zealand exemplar of the writerly life, and her walk-out story can be read as providing practical instructions for building writing as a 'community of resistance'. Frame's walk-out story both describes how she effected her own resistance, and reproduces a moral tale about the writerly life: you can't have your foot in both camps at the same time - the Place of Judges and the Place of Language Resistance are antithetical.

To put it another way, telling the walk-out as an epiphany is a live piece of social sentiment. It forces a reaction in the reader; if one is a budding writer, it forces an immediate empathic response, not a judgement in terms of rationality or beliefs. As Rawls states, 
Enacted practices are not beliefs. They do not succeed by creating the appearance that they have succeeded. The enacted practices must 'really' produce the requisite feelings or sentiments for the whole group, or they fail. ... the basic concepts required for shared intelligibility are created by producing visibly and hearably recognizable practices that produce identical feelings in all participants simultaneously. (2001: 36)

Hence to suggest, as King does, that Frame may not have the told the events in the correct order, is to miss the point of the story. In telling the walkout as epiphany, Frame and Evans do not 'believe' they are telling the truth; they are actually producing live emotions and feelings about how writers are created. This is done directly in the form and content of the story. Thus, we are looking at some possible materials for the building of writing culture: 'A culture is, in fact, where we recognise what you are doing because, for all of us, culturally, that is how we would do it' (Miller and McHoul, 1998: 179). All of this is not to say that there has to be agreement about how we read the Frame walk-out story; it is to say that we feel it is the right one, immediately as we read it. With Frame walking-out there is a near perfect fit between the story and the life: we know that this is how writers live out the writerly life, or more to the point, how they are turned into imaginative beings.

At the very end of Wrestling with the Angel, King introduces Frame's latest move of house to St Kilda, Dunedin, noting that:

Here too she completed discussions with her biographer, telling her life in a tone that acknowledged past tragedies but seemed more frequently to tremble on the brink of laughter ... her voice and articulation remained bell-clear, almost childlike. Key words were hesitated over, as if he and her interlocutor should pause to marvel over the huge adventure they were engaged in: the possibility of recreating the past [emphasis added] and finding meaning there through the device of linguistic communication. Talking and writing, she conveyed a vivid sense that reality itself is a fiction, and one's grasp on it no more than preposterous pretence and pretension. And that sense delights her, as it does her readers and listener... As always, she feels most herself at the keyboard, transforming thought, feelings, dreams and memory, pushing the possibilities of language to their furthest limits ... [here] she rediscovers the world and engages with it, without the burden of social contact. (2000: 518-519) 
I have no desire to criticise King's obvious historical-style biography ${ }^{2}$, but it is important to add a comment here. Whatever your stance on the issue of whether we can recreate the past, it can be emphasised that moral tales and parables are primarily aimed at shaping the future. They are guidelines for future activity, and as such we can read the Frame walk-out story as a guideline for the construction of the imaginative life. In short, here is a literary icon exhorting budding writers to 'take the plunge'.

Finally, we can dwell upon the notion of writing 'without the burden of social contact'. Sitting writing at a computer does not fall within the realm of face-toface interaction, but it is still a social activity. Consider two people standing face-to-face in the middle of a broad footpath, engaged in conversation. There is space for you to easily walk between them. But of course you do not, for there is something powerful circulating between the two speakers. It is not material, but its force is such that you will not pass through and break the chain of conversation. It is exactly in this way, when considering the Frame walk-out story, that we need to move beyond individualism. Reading King's life of Frame, we do see the emerging identity battered and bruised by parental and other egos, we hear from the now successful psychologist on the forces shaping identity, then we see the empowered author wilfully playing with language, avoiding Judgement, adding nuance after nuance (and of course there is the authentic biographer directly witnessing the life being constructed). But what should not be forgotten in this is the brute power of the social, that nebulous entity that takes up both individuals and language and melds them within moral force fields. For sheer economy of style, there is little to match Frame's and Evans' versions of the walk-out story. They are the moral tale equivalent of the gripping newspaper headline: in the space of a few sentences they introduce the elements, and make their point, with no doubt as to their moral upshot. It is a rare person who comes between, who questions, the received wisdom of moral tales and parables. The 'seen but unnoticed' power of such tales is through and through social; Janet Frame does not own it, she uses it to engage a community of readers, or more correctly, a community of writers-to-be, who are provided with a story and a guideline for how to construct the imaginative life, in contrast to the ordinary world of judgement. How many fall by the wayside and unravel after a walkout is unknown, but even if it is the majority, it does not weaken the power of the walking-out narrative.

\footnotetext{
${ }^{2}$ Wilkins (2001) provides an interesting review of King's book. I must admit, I find the critical edge of his review convincing. I discovered his review after writing this article, and so was unable make greater use of it here.
} 


\section{Works Cited}

Bell, Claudia. Sociology of Everyday Life in New Zealand. Palmerston North: Dunmore Press, 2001.

Evans, Patrick. Janet Frame. Boston: Twayne, 1977.

Evans, Patrick. 'The Muse as Rough Beast.' Untold 6 (Spring 1986): 1-10.

Frame, Janet. 'Beginnings.' Landfall 19 (March 1965): 40-47.

Frame, Janet. An Angel at My Table. An Autobiography: Volume Two. Auckland: Hutchinson, 1984.

King, Michael. Wrestling With the Angel: A Life of Janet Frame. Auckland: Viking, 2000.

O'Sullivan, Vincent. ' "Better to Tell it All".' New Zealand Books 10 (October 2000): 1,3 .

McHoul, Alec and Miller, Toby. Popular Culture and Everyday Life. London: Sage, 1998.

Rawls, Anne. 'Durkheim's Treatment of Practice.' Journal of Classical Sociology 1 (2001): 33-68.

Wilkins, Damien. 'In the Lock-Up: Michael King's Biography of Janet Frame.' Landfall 201 (2001): 26-36. 